\title{
Diagnóstico para melhoria contínua nas Bibliotecas Escolares do município de Indaial/SC
}

\author{
Diagnostic for continuous improvement of school libraries Indaial city/SC
}

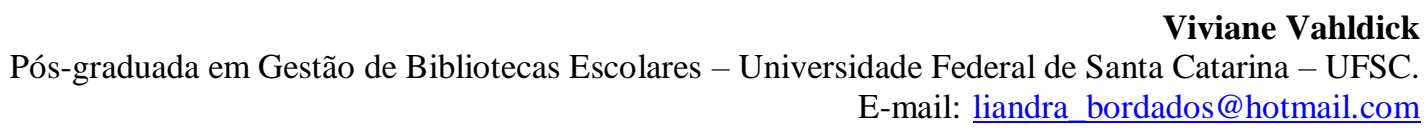

William Barbosa Vianna

Doutor em Engenharia da Produção - Universidade Federal de Santa Catarina - UFSC. Professor do Departamento de Ciência da Informação da Universidade Federal de Santa Catarina - UFSC.

E-mail: william.vianna@ufsc.br

\begin{abstract}
Cezar Karpinski
Doutor em História pela Universidade Federal de Santa Catarina - UFSC. Professor da Universidade Federal da Integração Latino-Americana - UNILA.

E-mail: cezark@hotmail.com
\end{abstract}

Marli Dias de Souza Pinto

Doutora em Engenharia da Produção pela Universidade Federal de Santa Catarina - UFSC. Professora Adjunta do Departamento de Ciência da Informação da Universidade Federal de Santa Catarina -

UFSC.

E-mail: $\underline{\text { marli.dias@ufsc.br }}$

\begin{abstract}
Resumo
O objetivo do estudo é diagnosticar oito (08) bibliotecas escolares do município de Indaial/SC para subsidiar a elaboração de um plano de melhoria baseado na proposta da IFLA e da Lei 12.244/10. Justifica-se pela necessidade de avançar em práticas e políticas públicas que fomentem a qualidade da educação e pela existência de um estudo preliminar realizado em 2006. Trata-se de pesquisa qualitativa, indutiva e que utiliza como instrumentos de intervenção questionários, entrevistas e observação in loco. Como resultado, identificaram-se pontos fortes, pontos fracos, ameaças e oportunidades. Conclui-se que, com o diagnóstico das bibliotecas escolares pesquisadas, é possível elaborar um plano de melhorias e até mesmo iniciar um planejamento estratégico para o município.
\end{abstract}

Palavras-chave: Gestão da informação. Gestão da qualidade. Melhoria contínua. Biblioteca escolar. Bibliotecário escolar.

\begin{abstract}
The objective of the study is to diagnose of eight (08) municipals school libraries in the Indaial municipality, Santa Catarina State, Brazil, to support the development of an improvement plan based on the proposal of IFLA and Brazilian Law No. 12,244/10. Is justified by the need to advance public policies and practices that promote the quality of education, and the existence of a preliminary study in 2006. The research is characterized as qualitative, inductive and uses questionnaires, interviews and on-site observation. Resulted in the identification of strengths, weaknesses, threats and opportunities. The study concluded that, with the diagnosis of school libraries surveyed, is can develop an improvement plan and even start a strategic plan for the municipality.
\end{abstract}

Keywords: Information management. Quality management. Continuous improvement. School library. School librarian. 


\section{Introdução}

As bibliotecas escolares, tendo em vista um atendimento cada vez mais qualificado de seus usuários, demandam processos de melhoria contínua em diversos aspectos de sua estrutura e funcionamento. A melhoria contínua (kaizen) tem sido importante por apresentar resultados significativos e ser a base de conduta para melhorar a performance de organizações bemsucedidas (SHIBA; GRAHAM; WALDEN, 1997).

Para Bessant e Caffyn (1997), a melhoria contínua pode ser definida como um processo de inovação incremental, focada e contínua, envolvendo toda a organização com pequenos passos, frequência contínua e pequenos ciclos de mudanças que, vistos separadamente têm pequenos impactos, mas somados podem trazer uma contribuição significativa para o desempenho organizacional.

No caso específico das bibliotecas escolares, a Federação Internacional de Associações de Bibliotecários e Instituições - IFLA (2005, p. 4), estabelece linhas fundamentais que orientam a melhoria contínua: a) a biblioteca escolar necessita de políticas bem estruturadas que fomentem o gerenciamento racional e sustentável e devem contar com a participação de toda a comunidade escolar; b) uma nova cultura passa a ser construída pois é a biblioteca escolar que habilita os alunos para a aprendizagem ao longo da vida e desenvolve sua imaginação, preparando-os para viver como cidadãos responsáveis.

No Brasil, tem-se ainda a Lei 12.244/10 que dispõe sobre a universalização das bibliotecas nas instituições de ensino e determina que todas as escolas do país possuam uma biblioteca. Essas, por sua vez, devem contar com materiais videográficos e documentos registrados em qualquer suporte destinados a consulta, pesquisa, estudo ou leitura, dentre as quais se encontram também as bibliotecas das escolas municipais.

Subsidiar e orientar a melhoria contínua em bibliotecas escolares demanda diagnósticos capazes de identificar aspectos a serem melhorados em determinados recortes de tempo, tendo em vista a identificação de elementos para elaboração de um plano de melhorias e posteriormente a análise de sua eficácia orientada pelos objetivos pretendidos.

Nesse sendo, pergunta-se: como se encontram as Bibliotecas Escolares do Município de Indaial em relação às propostas da IFLA (2002) e Lei 12.244/10? 
Viviane Vahldick, William Barbosa Vianna, Cezar Karpinsky e Marli Dias de Souza Pinto

O objetivo do estudo é identificar elementos para um diagnóstico da realidade de oito (08) bibliotecas municipais, aderentes à proposta, para subsidiar a elaboração de um plano de melhoria baseado na proposta da IFLA e da Lei 12.244/10. Justifica-se pela necessidade constante de melhorias nas Bibliotecas Escolares tendo em vista o atendimento dos estudantes e de toda a comunidade.

A escolha pelo Município de Indaial foi facilitada pelo fato de que, no ano de 2006, foi realizado um estudo preliminar para identificar como estavam as bibliotecas das escolas da rede municipal de ensino, principalmente nos aspectos de oferta de produtos e serviços aos estudantes e usuários. Na época, optou-se pela amostragem de oito (08) escolas, dentre 13, sendo essas as que aceitaram participar do projeto naquele período. Identificou-se que as Bibliotecas Escolares estavam aquém do esperado, ou seja, não estavam "preparadas o suficiente para atender o educando, tanto na pesquisa quanto na literatura no ambiente escolar". (VAHLDICK; JUNGBLUT, 2007, p. 115).

Sendo assim, entendeu-se que seria útil uma revisão da realidade dessas escolas, para melhor verificar eventuais avanços ou lacunas que persistiram na organização e na gestão da qualidade das bibliotecas escolares do município.

Embora algumas comparações sejam feitas em alguns momentos neste trabalho, o artigo apresenta, detidamente, os resultados advindos do estudo atual, não se caracterizando estritamente por um estudo comparativo, mas um diagnóstico da realidade de 2015.

Trata-se de uma pesquisa aplicada, qualitativa e experimental que se baseia em dados atuais para a análise de uma situação específica. Caracteriza-se também como pesquisa indutiva, isto é, o pesquisador desenvolve entendimentos a partir de padrões encontrados nos dados (questionário, entrevistas e observação), ao invés de coletar dados para comprovar teorias, hipóteses e modelos pré-concebidos.

Como instrumento de intervenção utilizou-se para coleta de dados um questionário, entrevistas semiestruturadas e a observação.

Primeiramente foi aplicado o questionário semiestruturado que possibilitasse a verificação do atendimento das diretrizes da IFLA e das normas básicas de gestão das bibliotecas escolares frente à Lei 12.244/10. 
Diagnóstico para melhoria contínua nas Bibliotecas Escolares do município de Indaial/SC

Em seguida, entrevistaram-se os servidores municipais responsáveis pela organização, gestão e serviços destas bibliotecas e, nas visitas in loco, observou-se aspectos de infraestrutura, localização, gestão, serviços e perfil dos profissionais atendentes.

\section{As Bibliotecas Escolares no contexto histórico das bibliotecas ocidentais}

Ao historiar o processo que levou a humanidade das primeiras expressões gráficas à era digital, Martins (1998) destaca o lugar que a biblioteca ocupou ao longo desta história. Segundo este autor, por mais paradoxal que possa parecer, a história da biblioteca é anterior à do próprio livro ou dos manuscritos. Neste sentido, pode-se afirmar que, desde os primórdios, a biblioteca se constituiu como um lugar do conhecimento naquilo que, para muitas civilizações antigas, traduzia-se como o espaço do poder supremo. As primeiras expressões escritas simbolizavam as representações do divino, dada a possibilidade de tornar material o que, até então, só se reproduzia oralmente.

No entanto, é certo que, a partir da imprensa e da produção serial de livros na forma moderna, a biblioteca ganhou outros contornos e utilidades, mas não se afastou do caráter cultural e de ser um repositório de conhecimento. Segundo Battles (2003, p. 23) a sociedade moderna percebeu "que a plenitude de uma cultura está expressa em sua literatura tomada como um todo. Os autores de livros logo pressentiram a importância da biblioteca".

Para além da influência e do fascínio que as bibliotecas exerceram sobre as sociedades antigas e medievais, foi necessária uma nova forma de acesso a estes espaços que, até bem pouco tempo atrás, se restringia às elites. Um dos autores que muito contribui para a percepção do processo histórico de democratização da leitura e das bibliotecas é o historiador francês Roger Chartier. A partir do que chamou "história da leitura" Chartier expôs em várias de suas obras a construção histórica do gosto pela leitura e a constituição das bibliotecas como lugares sociais e públicos. Em A aventura do livro: do leitor ao navegador, por exemplo, este autor discute exatamente este assunto, historiando os momentos cruciais de uma cultura moderna que possibilitou práticas de acesso à leitura pública, principalmente a expansão do modelo estadunidense. Nessa concepção, a leitura pública supõe que a biblioteca saia de seus muros e vá ao encontro dos leitores. (CHARTIER, 1998, p. 123).

Para tornar possível esse ideal, modificaram-se as formas de planejamento, a gestão e o acervo as bibliotecas e, já no Século XX, passam a ser pensadas a partir da noção de usuário. 
Viviane Vahldick, William Barbosa Vianna, Cezar Karpinsky e Marli Dias de Souza Pinto

Fonseca (1992, p. 65) informa que foi nesse contexto que as bibliotecas foram divididas em categorias de atendimento: "a biblioteca infantil, a biblioteca escolar, a biblioteca universitária, a biblioteca especializada e a biblioteca nacional”.

Com relação à biblioteca infantil, Chartier e Hébrard (1995, p. 170) explicam que uma das metas desta categoria de bibliotecas é "colocar as crianças num ambiente 'cultural' rico e variado, onde possam construir sua formação de leitor".

Acrescentam ainda que

[...] a diferença entre a biblioteca infantil e a biblioteca escolar, além da riqueza dos acervos, é evidentemente o conhecimento do bibliotecário, que leu todos os livros que ela propõe e pode assim falar sobre eles a cada criança, quando solicitado. Além disso, tem-se a familiaridade dos jovens leitores com as múltiplas atividades organizadas nos locais (exposições, leitura em voz alta, círculos de poesia e de conto) [...]. (CHARTIER; HÉBRARD, 1995, p. 171).

$\mathrm{Na}$ visão dos autores, o que distingue a biblioteca infantil da biblioteca escolar é a presença do bibliotecário e um rico do acervo. A ênfase dada ao bibliotecário demonstra que seu perfil profissional habilita os estudantes em fase escolar para a leitura, por meio de práticas e estratégias de gestão e serviços, transformando a biblioteca no lugar que lhe é devido nas escolas. Conhecer o acervo, valorizar a biblioteca, estimular os alunos, criar competências específicas para este espaço dentro das políticas pedagógicas, faz do bibliotecário, juntamente com os professores, um agente transformador no processo ensino-aprendizagem.

Além da leitura em voz alta, dos círculos de poesia e de conto, como sugerem Chartier e Hébrard, a inserção do bibliotecário nas bibliotecas escolares faz com que a renovação do acervo, por exemplo, advenha de um conhecimento profundo da realidade escolar. Obedecendo as fases da educação básica na gestão dos serviços, a biblioteca escolar se torna um lugar prazeroso, de fácil acesso e de acordo com as especificidades destes alunos. De certa forma, estas ações corroboram para o que Torres (1989) já chamava de bibliotecas operacionais e dinâmicas:

[...] a ideia de uma biblioteca "operacional" necessariamente [...] deve estar voltada aos interesses dos seus usuários, dando-lhes respostas imediatas às suas dúvidas e questionamentos [...] a biblioteca "dinâmica" será aquela que procurará desenvolver atividades culturais $[\ldots]$ bem como tomará a iniciativa de "correr atrás" do estudante senão ficará à espera dele. (TORRES, 1989, p. 32).

Nesse contexto e com apoio destas perspectivas, pesquisou-se, no município de Indaial - SC, como se apresentam as bibliotecas escolares selecionadas. Tendo como ponto de partida o estudo feito em 2006 e as mudanças nas políticas educacionais brasileiras no que diz respeito 
Diagnóstico para melhoria contínua nas Bibliotecas Escolares do município de Indaial/SC

às bibliotecas escolares, apresenta-se o estágio de desenvolvimento na gestão e serviços. Além disso, os dados levantados fornecem subsídios para verificação do atendimento ou não das diretrizes da IFLA/UNESCO.

\section{Planejamento e organização das Bibliotecas Escolares}

A gestão das bibliotecas escolares deve responder às necessidades da comunidade em que está inserida, e a escola é a responsável em reafirmar e formalizar esta importância no processo de ensino- aprendizagem. Sendo assim, "a escola pode colaborar na formação do leitor, e sua colaboração será maior ou menor na dependência dos pressupostos que fundamentam o seu currículo" (MOLINA, 1992, p. 12).

A partir do entendimento de que a biblioteca escolar é local de aprendizagem, a escola deve, em seu planejamento e organização, privilegiar o uso e acesso à informação. Assim, a biblioteca se torna uma extensão da sala de aula, cuja responsabilidade e gestão sejam de um bibliotecário, pois este é o profissional preparado para trabalhar neste espaço.

Deste modo, o planejamento e o projeto pedagógico, com organização e criatividade, inserem a biblioteca escolar como um espaço de aprendizagem em que se impõem a socialização do saber, o incentivo à leitura e o desenvolvimento do leitor.

\subsection{Rede de ensino e o escopo da pesquisa}

A rede de ensino do município de Indaial abrange vinte e quatro (24) Unidades de Educação Infantil e treze (13) Escolas Básicas de Ensino em diferentes bairros. As primeiras atendem crianças de 0 a 6 anos, também possuem acervos literários de boa qualidade, mas em muitas delas apenas os professores têm acesso. As crianças só têm contato com os livros na sala, com os momentos de leitura, ou quando a sala possui um espaço de aprendizagem denominado "Cantinho da Leitura".

Assim, neste item, apresentam-se as análises feitas a partir de visitas técnicas e entrevistas com os profissionais responsáveis pelas Bibliotecas Escolares estudadas. Esta metodologia foi utilizada tanto para ouvir e registrar os relatos destes servidores quanto para observação pessoal sobre a qualidade da infraestrutura e organização dos espaços apresentados a seguir. 
Viviane Vahldick, William Barbosa Vianna, Cezar Karpinsky e Marli Dias de Souza Pinto

\subsubsection{Formação e dinâmicas exercidas pelos profissionais das Bibliotecas Escolares}

As bibliotecas escolares estudadas não possuem profissionais com formação acadêmica em Biblioteconomia. São todos professores que são readaptados ou convidados para exercer função neste espaço. Estes professores que atuam nas bibliotecas escolares do município de Indaial têm Ensino Superior nas áreas de: Geografia, Pedagogia, Letras Português/Italiano/Espanhol) e alguns deles com Pós-graduação: Metodologia de Ensino, Especialização em Séries Iniciais, Gestão Escolar.

As atividades que estes professores desenvolvem buscam estimular a frequência dos estudantes à biblioteca e incentivar a prática de leitura. As principais dinâmicas são: contação de histórias para os alunos de $1^{\circ}$ ano ao $5^{\circ}$ ano com diversas técnicas de leitura; troca de livros semanalmente ou quinzenalmente para todos os estudantes por meio de autorização de responsabilidade dos pais; auxílio de pesquisa para projetos feitos em conjunto com os professores.

Além destas atividades voltadas à leitura, os profissionais também possuem grupos de teatro, fazem fotocópia, auxiliam os professores quando os estudantes possuem dificuldades em leitura e escrita. Percebe-se também que há interação nos projetos institucionais da Escola, tais como: dia da poesia, dia do livro, homenagens cívicas e datas comemorativas, festival literário do município e projetos da Associação de Pais e Professores (APP).

Pode-se afirmar que nem todos os profissionais atuam apenas na biblioteca. Além disso, as entrevistas mostram que estes profissionais estão cumprindo parcialmente os deveres do bibliotecário definidos nas Diretrizes da IFLA/UNESCO para a Biblioteca Escolar:

\footnotetext{
a) analisar os recursos e as necessidades de informação da comunidade escolar; b) formular e implementar políticas para o desenvolvimento de serviços; c) desenvolver políticas de aquisição e sistemas para os recursos da biblioteca; d) catalogar e classificar materiais da biblioteca; e) oferecer instruções no uso da biblioteca; f) capacitar profissionais e alunos no conhecimento e uso da informação; g) prestar atendimento a estudantes e professores no uso dos vários recursos da biblioteca e das tecnologias de informação; h) responder a questões de referência e informação, utilizando materiais apropriados; i) promover programas de leitura e eventos culturais.
}

São professores que agregam em suas funções competências para as quais não foram preparados, embora consigam cumprir minimamente com as atividades. No entanto, pelo exposto até aqui, pode-se inferir que o profissional que atua nas Bibliotecas Escolares é um animador cultural que exerce também a função de cuidar e zelar da biblioteca. 
Diagnóstico para melhoria contínua nas Bibliotecas Escolares do município de Indaial/SC

\subsubsection{A Biblioteca Escolar no Projeto Político Pedagógico}

O Projeto Político Pedagógico - PPP é um dos documentos mais importantes das escolas, pois nele estão contidos os eixos norteadores do ensino e funcionamento da instituição escolar. Conforme as Diretrizes da IFLA/Unesco e da política nacional de educação, é essencial que o PPP enfatize as estratégias de ensino relacionando-os às bibliotecas escolares. Contudo, a realidade encontrada nas escolas selecionadas não condiz com estas normativas. Alguns estão desatualizados diante da realidade atual das bibliotecas e outros nem chegam a citá-las.

O PPP, no item sobre a biblioteca escolar, deveria estabelecer ou elaborar as finalidades com os seus objetivos, necessidades, indicadores de uso / de recursos / de pessoas. Além desta parte pragmática, deveria compor também o documento a inserção da biblioteca no contexto histórico da escola, com um nome significativo para aquela comunidade. No caso de Indaial, somente foi possível descobrir os nomes das Bibliotecas Escolares a partir das entrevistas, conforme descrevemos no Quadro 01.

\section{Quadro 01 - Identificação das Bibliotecas Escolares}

\begin{tabular}{|l|l|}
\hline Instituição de Ensino & Nome da Biblioteca \\
\hline Colégio Municipal de Indaial & Biblioteca Municipal Rachel de Queiroz \\
\hline Escola Básica Municipal Leopoldo Simão & Biblioteca Municipal Aurea Bonatti Merini \\
\hline $\begin{array}{l}\text { Escola Básica Municipal Professora Maria da Graça dos } \\
\text { Santos Salai }\end{array}$ & Biblioteca Municipal Fonte do Saber \\
\hline Escola Básica Municipal Tancredo de Almeida Neves & Biblioteca Municipal Cecília Meireles \\
\hline Escola Básica Municipal Encano Baixo Rudolf Alfarth & $\begin{array}{l}\text { Biblioteca Municipal Carlos Drummond de } \\
\text { Andrade }\end{array}$ \\
\hline Escola Básica Municipal Anna Alves Dias & Biblioteca Municipal Manoel Bandeira \\
\hline Escola Básica Municipal Arapongas & Biblioteca Municipal Mario Quintana \\
\hline Escola Básica Municipal Mulde Baixa & Biblioteca Municipal Doraci Schubert \\
\hline
\end{tabular}

\subsubsection{Horário de funcionamento}

As Bibliotecas Escolares pesquisadas têm seu horário de funcionamento condicionado ao horário da Escola. No período matutino, todas as bibliotecas visitadas funcionam das 7h30m as $11 \mathrm{~h} 30 \mathrm{~m}$. Já no período vespertino, a organização do horário é estabelecida pelo funcionário do setor. Foram detectados três horários distintos: das $13 \mathrm{~h}$ às $17 \mathrm{~h}$; das $13 \mathrm{~h} 30 \mathrm{~m}$ às $17 \mathrm{~h} 30 \mathrm{~m}$; e das $12 \mathrm{~h} 45 \mathrm{~m}$ às $16 \mathrm{~h}$.

Nas escolas de Indaial, o intervalo em ambos os períodos está organizado de forma que primeiramente tenham intervalo os alunos do $1^{\circ}$ ao $5^{\circ}$ ano e, quando estes voltam à classe, 
Viviane Vahldick, William Barbosa Vianna, Cezar Karpinsky e Marli Dias de Souza Pinto

ocorre o intervalo das turmas do $6^{\circ}$ ao $9^{\circ}$ ano. Independente do horário de funcionamento das bibliotecas, apenas este último grupo tem acesso livre à biblioteca escolar.

\subsubsection{Aquisição e descarte do acervo}

A formação do acervo da biblioteca escolar deve ser planejada como previsto na Lei $\mathrm{n}^{\circ}$ 12.244 de 24 de maio de 2010, Art. $2^{\circ}$, parágrafo único:

Será obrigatório um acervo de livros na biblioteca de, no mínimo, um título para cada aluno matriculado, cabendo ao respectivo sistema de ensino determinar a ampliação deste acervo conforme sua realidade, bem como divulgar orientações de guarda, preservação, organização e funcionamento das bibliotecas escolares. (BRASIL, 2010)

Pode se verificar pelo estudo que todas as 8 (oito) bibliotecas das escolas municipais de Indaial cumprem o Art. $2^{\circ}$ da Lei 12244/10, evidenciado acima.

Com esta questão do questionário também foi possível respostas unânimes de que o acervo supre a quantidade necessária na proporção de estudantes de cada instituição de ensino, por meio de livros que recebem do Programa Nacional Biblioteca da Escola. Também com o apoio da Associação de Pais e Professores e da Direção da Escola com livros indicados tanto pelos professores como pelos estudantes. Além disso, a Secretária de Educação de Indaial cumpre com sua parte ao solicitar aos profissionais da Biblioteca uma relação de livros para aquisição. Também recebem doações de livros da comunidade.

Outra forma de ampliação do acervo é advinda dos recursos captados pelo atraso dos livros. Os estudantes que atrasam a devolução do livro, pagam multa simbólica entre R $\$ 0,30$ à $\mathrm{R} \$ 0,50$ por dia de atraso. Estes valores são revertidos para aquisição de materiais para a biblioteca. Já quando perdem ou danificam o livro, os alunos devem trazer outro livro com o mesmo título ou ser quase do mesmo valor do livro que não devolveram.

$\mathrm{Na}$ questão como avaliam o acervo para descarte estes informaram que contam com o auxílio da coordenadora geral das bibliotecas do município para esta atividade. Além disso, utiliza-se como critérios de descarte a observação da presença de agentes ambientais (mofo).

No entanto, para a aquisição, doação ou eliminação do acervo deveria se constituir uma comissão de avaliação na própria escola para criar critérios para tal e qual a necessidade. Não ficando apenas para o profissional da biblioteca esta avaliação e decisão. Neste sentido, Peres e Silveira (1998, p. 126) afirmam que: “[...] há necessidade de criarmos uma normatização, 
chamada tecnicamente de "Política de Seleção de Materiais de Informação", para atingir uma melhor qualidade na formação da respectiva coleção, dentro das disponibilidades e recursos existentes na Instituição na qual a biblioteca está inserida”.

\section{As Bibliotecas Escolares de Indaial e as Diretrizes da IFLA/UNESCO}

Além das análises relacionadas à gestão, serviços, planejamento e organização das Bibliotecas Escolares de Indaial, buscou-se perceber se sua infraestrutura condiz com as normativas vigentes. Foram observados critérios especificados nas Diretrizes da IFLA/UNESCO sobre os seguintes aspectos: indicadores de uso, localização e espaço, móveis e equipamentos, equipamentos eletrônicos e audiovisuais e recursos eletrônicos. Com estes dados, foi possível uma análise comparativa com o estudo de Vahldick e Jungblut (2007) onde se constatou que as bibliotecas escolares de Indaial não estavam "preparadas o suficiente para atender aos seus educandos" tanto na área da gestão quanto da infraestrutura. (VAHLDICK; JUNGBLUT, 2007, p. 115).

Segundo os mesmos autores, estas bibliotecas escolares apresentavam sérios problemas. Os espaços destinados às bibliotecas eram pequenos e com pouca ventilação, havia poucos projetos de incentivo a leitura, a iluminação era insuficiente, o mobiliário inadequado, o acervo de baixa qualidade e desorganizado. Nos serviços, evitava-se o empréstimo para a comunidade escolar, desvalorizando assim o papel crucial deste espaço no processo ensino-aprendizagem. Embora

[...] não haja "medida universal e única para as instalações da biblioteca escolar [...] é útil e proveitoso ter algum tipo de fórmula para cálculos de planejamento, de modo que qualquer nova biblioteca ou uma biblioteca remodelada possa atender às necessidades da escola com mais eficiência. (IFLA/UNESCO, 2005, p. 28)

No caso em tela, o questionário semiestruturado e a visita in loco possibilitaram um diagnóstico da atual situação das bibliotecas escolares de Indaial, no que diz respeito às diretrizes da IFLA/UNESCO. Para este artigo, destacam-se alguns itens sobre "missão e política", "Recursos" e "Atividades na escola". Sobre a primeira, optou-se por analisar o indicador de uso "empréstimo" como recurso de planejamento da "supervisão e avaliação da biblioteca". Já em relação aos recursos, a opção foi a de diagnosticar os quesitos de "localização e espaço", "móveis e equipamentos", "equipamentos eletrônicos e audiovisuais" e "recursos eletrônicos". Sobre as atividades, buscaram-se informações sobre os tipos de atividades desenvolvidas em torno da biblioteca na escola. (IFLA/UNESCO, 2005).

Bibl. Esc. em R., Ribeirão Preto, v. 5, n. 2, p. 43-59, 2017. 


\subsection{Missão e Política}

Segundo a IFLA/UNESCO (2005, p. 4), para que a Biblioteca cumpra com sua missão de propiciar informação e ideias, ela deve ser "gerenciada dentro de um quadro de políticas claramente estruturado". Por meio de ações práticas e conjuntas de toda a comunidade escolar, é possível estabelecer metas, dificuldades, necessidades e a supervisão e avaliação contínua. Neste sentido, entre os indicadores que contribuem para essa prática avaliativa estão os indicadores de uso, ou seja, os registros que tornam visíveis a inserção da biblioteca na comunidade escolar. Neste estudo, optou-se por verificar o indicador de uso "registro de empréstimos".

Das 08 bibliotecas analisadas, apenas uma não registra de forma sistemática seus empréstimos, as demais, possuem programas específicos de registro que possibilitam estatísticas sobre esta atividade.

\subsection{Recursos}

Os recursos financeiros destinados a uma biblioteca escolar devem ser suficientes para garantir recursos humanos, materiais, tecnologias e instalações adequadas. Somente assim, é possível qualificar o serviço e garantir seu acesso de forma gratuita. (IFLA/UNESCO, 2005, p. 6). Em Indaial, pesquisaram-se os seguintes itens nesta categoria: localização e espaço; móveis e equipamentos; equipamentos audiovisuais; e recursos eletrônicos.

\subsubsection{Localização e espaço}

Fatores como acessibilidade, ruído, iluminação, climatização, espaço físico e área específica para leitura contribuem consideravelmente para o bem-estar e, consequentemente, a procura, pelo aluno, à biblioteca. Sobre a acessibilidade, é importante notar se a biblioteca se encontra em local visível e no andar térreo. A escolha pelo local, deve se dar de forma estratégica para que não seja um espaço de barulho, que seja bem iluminado e garantindo uma temperatura constante que possibilite o bem-estar dos usuários. O espaço deve ser do tamanho necessário para acondicionar o acervo e proporcionar locais específicos para leitura.

Sobre a acessibilidade, as 08 bibliotecas pesquisadas estão localizadas no andar térreo, o que facilita a utilização pelos alunos portadores de necessidades especiais. Contudo, 05 delas 
encontram-se na parte mais longínqua da escola, o que não facilita a constante visualização por parte dos alunos.

O fator "ruído" ou barulho externo foi observado em 02 escolas. Sendo que, em 01 delas o ruído é constante por estar situada ao lado da quadra poliesportiva utilizada tanto nos horários de aula para educação física, quanto nos horários de intervalo para a prática de esportes e outras atividades lúdicas.

Segundo a IFLA/UNESCO (2005, p. 8) a "iluminação deve ser suficiente e apropriada, por meio de janelas ou luz artificial". Neste requisito, atendem satisfatoriamente 06 bibliotecas, em parte 01 e insatisfatoriamente 01. Com relação ao espaço físico e à área específica para leitura, todas as bibliotecas obedecem às diretrizes da IFLA/UNESCO, pois as salas são espaçosas, garantindo tanto o bom acondicionamento do acervo quanto as atividades específicas desenvolvidas.

\subsubsection{Móveis e equipamentos}

Neste item a observação se concentrou no mobiliário e na estética. Sobre os móveis buscou-se perceber se o conforto dos assentos, se as mesas são adequadas às especificidades da escola e as estantes de material que garantam a segurança e qualidade do acervo. Apenas 04 das escolas atendem esse critério, 03 atendem em parte e 01 não atende.

Segundo a IFLA/UNESCO (2005, p. 9) “a aparência estética promove uma sensação de acolhimento da comunidade escolar, trazendo incentivo para que ela permaneça por mais tempo na biblioteca". Contudo, é difícil estabelecer um padrão estético, principalmente pelos diferentes aspectos culturais dos gestores e pesquisadores. Para este item, levou-se em consideração, principalmente, a orientação da IFLA/UNESCO de que ser esteticamente agradável está relacionado à “orientação e sinalização claras e atrativas, de modo a proporcionar boa ambientação de lazer e aprendizagem para os usuários”. Em Indaial, apenas 03 bibliotecas escolares atendem esta diretriz, as outras 05 atendem em parte. 


\title{
4.2.3 Equipamentos eletrônicos e audiovisuais
}

\begin{abstract}
A biblioteca escolar desempenha importante função como porta de acesso à atual sociedade baseada na informação e no conhecimento. Por essa razão, deve prover o acesso a todos os equipamentos eletrônicos, computacionais e audiovisuais necessários. (IFLA/UNESCO 2005, p. 9)
\end{abstract}

A partir das análises, percebeu-se que as bibliotecas estudadas apresentam um déficit considerável quando se trata de equipamentos eletrônicos e audiovisuais. Nenhuma das bibliotecas possui computadores e internet disponíveis aos usuários e apenas 03 possuem aparelhos de multimídia.

\subsubsection{Recursos eletrônicos}

Segundo a IFLA/UNESCO (2005, p. 11) é "vital escolher um sistema de catálogo para a biblioteca, que permita a classificação e catalogação dos recursos informativos de acordo com padrões bibliográficos aceitos nacional e internacionalmente". Nesta questão, observou-se como o profissional cataloga seu acervo e qual o sistema utilizado na Biblioteca. Na amostra foi possível perceber que apenas 02 não atendem este requisito, sendo que uma não possui um sistema e outra possui, mas não utiliza. Nestes dois casos, a catalogação é feita de forma manuscrita em livros de registro. Das 06 bibliotecas que possuem algum tipo de catalogação sistêmica, 04 utilizam o software MiniBiblio, 01 faz a catalogação no Programa Microsoft Office Excel e 01 faz a catalogação no MiniBiblio e no Excel.

\section{Atividades na escola}

A biblioteca escolar "deve desenvolver uma ampla variedade de atividades e ter funçãochave no cumprimento da missão e da visão da escola". Além disso, deve haver um planejamento de atividades que sejam capazes de atender "todos os usuários potenciais da comunidade escolar e a satisfação das necessidades específicas dos grupos-alvo" (IFLA/UNESCO, 2005, p.16).

Para que esta diretriz se estabeleça, é necessário um trabalho conjunto entre responsáveis pela biblioteca e os professores e diretores. Neste sentido, perguntou-se aos responsáveis pelas bibliotecas escolares de Indaial se havia atividades programadas pela 
Diagnóstico para melhoria contínua nas Bibliotecas Escolares do município de Indaial/SC

Biblioteca. O resultado apontou para 07 escolas que atendem este requisito e 01 que atende em parte.

Entre as atividades desenvolvidas se destacam as que visam promover a biblioteca, como hora do conto, contação de histórias, varal de livros, exposição de livros fora da biblioteca, hora da leitura. Além disso, todos os responsáveis pela biblioteca participam das atividades projetadas pela escola, principalmente as comemorações cívicas e dias especiais do ano. Sendo assim, é possível afirmar que inexiste planejamento de ações especificamente voltadas à biblioteca escolar, como sugere a IFLA/UNESCO.

\section{Considerações finais e Perspectivas de melhoria contínua}

Os processos de melhoria contínua necessitam ser constantes e os documentos que são construídos ao longo do tempo são fundamentais para subsidiar novos planos e sua avaliação.

No caso desse estudo, foi possível verificar melhorias nas oito (08) bibliotecas escolares da rede pública de ensino médio do município de Indaial/SC entre o primeiro estudo documentado em 2006 e o estudo atual em 2015.

Basicamente, foi possível verificar de forma majoritária: a) avanços e as melhorias percebidas na infraestrutura e serviços; b) há um profissional atendendo os usuários; c) quase todas apresentam número de livros compatíveis com as necessidades dos alunos; d) há espaços específicos para a leitura; e) há atividades de incentivo à leitura que garantem o início de um processo formador de leitores; f) quanto ao horário de funcionamento, o profissional permanece com a biblioteca aberta apenas para os estudantes do $6^{\circ}$ ao $9^{\circ}$ período.

Como ponto forte em relação ao acervo, destacou-se que o mesmo supre a quantidade necessária na proporção de estudantes de cada instituição de ensino, recebem livros do Programa Nacional Biblioteca da Escola (PNBE) da Secretaria de Educação Básica (SEB) do Ministério da Educação (MEC) bem como tem o apoio da Associação de Pais e professores e da Direção da Escola com livros indicados tanto pelos professores como pelos estudantes. Além disso, a Secretária de Educação de Indaial cumpre com sua parte ao solicitar aos profissionais da Biblioteca uma relação de livros para aquisição. Também recebem doações de livros da comunidade. 
Viviane Vahldick, William Barbosa Vianna, Cezar Karpinsky e Marli Dias de Souza Pinto

Quando aos serviços das 08 bibliotecas analisadas, apenas uma não registra de forma sistemática seus empréstimos, as demais, possuem software específico de registro e estatísticas.

Verificou-se que os profissionais responsáveis pela biblioteca promovem atividade que valorizam e atraem os estudantes. Dentre estas, a hora do conto, contação de histórias, varal de livros, exposição de livros fora da biblioteca, hora da leitura.

Observou-se ainda que, com relação à acessibilidade, as 08 bibliotecas pesquisadas estão localizadas no andar térreo, o que facilita a utilização pelos alunos portadores de deficiência. Dos fatores ambientais, 06 escolas privilegiaram as suas bibliotecas com espaços que promove o bem-estar dos usuários. Quanto ao espaço físico e a área específica para leitura, todas as bibliotecas atendem as diretrizes da IFLA/UNESCO, pois as salas são amplas com parâmetros adequados para o bom acondicionamento do acervo, faltando, porém, identificação física externa nas mesmas.

Como ponto fraco, frente as Diretrizes da IFLA e a Política Nacional de Educação, onde se prevê que a comunidade escolar assuma também seu papel na valorização e priorização da biblioteca no espaço escolar, verificou-se que a maioria das escolas de Indaial, o PPP está desatualizado diante da realidade atual das bibliotecas, sendo que alguns nem chegam a citálas.

Outro ponto fraco é a falta de uma política de desenvolvimento de coleção, com critérios técnicos de aquisição, doação e eliminação do acervo. Sugere-se que se constitua uma comissão de avaliação na própria escola.

Como uma ameaça frente à cultura digital, verificou-se que as bibliotecas estudadas apresentam um déficit considerável quando se trata de equipamentos eletrônicos e audiovisuais.

Nenhuma das bibliotecas possui computadores e internet disponíveis aos usuários. Apenas três possuem aparelhos de multimídia. A tecnologia de informação e rede é um importante aliada do processo de ensino-aprendizagem, cabendo ao município estabelecer metas para sanar esta deficiência.

Além disso, como principal ameaça, destaca-se que os profissionais que atendem na Biblioteca, apesar de esforçar-se para fazer o possível e agenciar as ações e serviços na biblioteca, não possuem formação acadêmica em Biblioteconomia. São todos professores que são readaptados ou convidados a exercer função neste espaço. Evidenciou-se que o profissional 
Diagnóstico para melhoria contínua nas Bibliotecas Escolares do município de Indaial/SC

que atua nas Bibliotecas Escolares é mais um animador cultural do que um gestor da informação.

Esse ponto poderia ser resolvido por meio de um projeto de segunda graduação adequado à realidade do interior do Estado, associado a Universidade Aberta do Brasil (UAB), por parte de Cursos de Biblioteconomia de Universidades Federais, Estaduais ou Comunitárias com apoio e subsídio financeiro do munícipio aos alunos, tornando uma ameaça numa grande oportunidade de melhoria.

Por fim, considera-se que o objetivo do estudo que foi identificar elementos para um diagnóstico da realidade de oito (08) bibliotecas municipais para elaboração de um plano de melhoria tendo por base as propostas da IFLA e da Lei 12.244/10, foi atingido. Com os elementos identificados é possível elaborar um plano de melhorias e até mesmo iniciar um planejamento estratégico para o munícipio estabelecer políticas de melhoria contínua em educação.

\section{Referências}

BESSANT, J. CAFFYN, S. High involvement innovation through continuos impovememnt. International Journal of Technology Management, v. 14, n. 3, p. 7-28, 1997.

BATTLES, M. A conturbada história das bibliotecas. São Paulo: Planeta, 2003.

BRASIL. Lei $\mathrm{n}^{\circ} 12.244$ de 24 de maio de 2010. Dispõe sobre a universalização das bibliotecas nas instituições de ensino do País. Diário Oficial da União, Brasília, 25 maio 2010. Disponível em: <https://www. planalto.gov.br/ccivil_03/_ato20072010/2010/lei/l12244.htm>. Acesso em: 05 maio 2015.

CHARTIER, A.; HÉBRARD, J. Discursos sobre a leitura: 1880-1980. São Paulo: Ática, 1995.

CHARTIER, R. A aventura do livro: do leitor ao navegador. São Paulo: UNESP/Imprensa Oficial do Estado, 1998.

FONSECA, E. N. Introdução à Biblioteconomia. São Paulo: Pioneira, 1992.

IFLA/UNESCO. Diretrizes da IFLA/UNESCO para a Biblioteca Escolar. 2005.

Disponível em : < http://www.ifla.org/files/assets/school-libraries-resourcecenters/publications/school-library-guidelines/school-library-guidelines-pt_br.pdf $>$. Acesso em: 30 maio 2016. 
MARTINS, W. A palavra escrita: história do livro, da imprensa e da biblioteca. Com um capítulo referente à propriedade literária. 3. ed. São Paulo: Ática, 1998. 48 v.

MOLINA, O. Ler para aprender: desenvolvimento de habilidades de estudo. São Paulo: E.P.U., 1992.

PERES, L. C.; SILVEIRA, M. I. S. Seleção, aquisição e descarte de materiais de informação para bibliotecas escolares: uma sugestão coerente com a atual realidade escolar.Revista ACB: Biblioteconomia em Santa Catarina, Florianópolis, v. 3, n. 3, p. 125-132, 1998. Disponível em: <http://www.brapci.ufpr.br/brapci/v/1188>. Acesso em: 07 jan. 2016.

SHIBA, S.; GRAHAM, A.; WALDEN, D. TQM: quatro revoluções na gestão da qualidade. Porto Alegre: Artes Médicas, 1997.

TORRES, J. M. O espaço cultural da biblioteca na escola. Revista Contexto \& Educação, Ijuí, ano 4, n. 13, p. 31-37, jan./mar. 1989.

VAHLDICK, V.; JUNGBLUT, C. A. Organização da Biblioteca Escolar: dificuldades e possibilidades na rede municipal de Indaial. Leonardo Pós, Blumenau, v. 3, p. 111-116, 2007.

Artigo submetido em: 23 mar. 2016

Artigo aceito em: 18 jul. 2016 